\section{Veteriner protozoolojide aşı uygulamalarına güncel yaklaşım}

\section{Current approach to vaccine applications in veterinary protozoology}

\section{ÖZET}

Hayvanlarda görülen protozoer enfeksiyonlar, önemli üretim kayılarına neden olur ve birçok protozoan parazit türü, zoonotik öneme sahiptir. Protozoer hastalıklarla mücadele etmenin en yaygın yolu, antiprotozoal ilaçların kullanılmasına dayanmaktadır. Bununla birlikte, gıda için yetiştirilen hayvanlarda antiprotozoan ilaç direnci ve ilaç kalıntılarının varlığ 1 dünyanın çeşitli yerlerinde protozoan kontrol programları için ana sorunlardan biri olarak ortaya çıkmıştır. Protozoer enfeksiyonları kontrol etmenin en verimli ve uygun maliyetli yolu, bu tür enfeksiyonları önlemek için hayvanları aşılamaktır. Aşılamanın başlangıç maliyeti yüksek olmasına rağmen, hayvanların aşılanmasından kaynaklanan uzun süreli bağışıklık, bu tür enfeksiyonları kontrol altına almak için daha ucuz ve etkili bir alternatif sunmaktadır. $\mathrm{Bu}$ derlemede veteriner protozoolojide aşı uygulamalarının mevcut durumu gözden geçirilmiştir.

Anahtar Kelimeler: Aşı, protozoa, kontrol, parazit

\section{ABSTRACT}

Protozoan infections in animals are liable for significant production losses, and lots of protozoan parasites are of zoonotic importance. The use of anti-protozoal drugs is the most common way to treat protozoan diseases. Nevertheless, anti-protozoan drug resistance and the prevalence of drug residues in food-producing animals in different parts of the world have emerged as one of the key problems for protozoan control programs. Vaccinating animals to control certain infections is the most reliable and costefficient way to control protozoan infections. Although the initial cost of vaccination is high long-term immunity from animal vaccination provides a cheaper and more reliable solution to infection control. With this review, the current status of vaccine applications in veterinary protozoology has been reviewed.

Keywords: Vaccine, protozoa, control, parasite

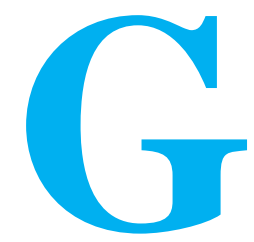

\section{IIRIŞ̧}

Hayvanlarda görülen protozoer enfeksiyonlar diğer paraziter hastalıklarda olduğu gibi, birçok ülkede tıbbi ve ekonomik yönden önemli sorunlara sebep olmaktadır. Bu önemli hastalıkları tedavi etmek için kullanılan etkili ilaçların mevcudiyetine rağmen, başarılı aşıların geliştirilmesine olan ihtiyaç devam etmekte, küreselleşmenin bu kadar hızlı seyrettiği dünyamızda, bu ihtiyaç giderek artmaktadır (Behr vd., 2016).

\section{How to cite this article}

Göksu, A., Çiçek H. (2021). Current approach to vaccine applications in veterinary protozoology. Journal of Advances in VetBio Science and Techniques, 6(2), 179-190. https://doi.org/ $\underline{10.31797 / \text { vetbio. } 882383}$
Review Article

\section{Ahmet GÖKSU ${ }^{1 \mathrm{a}}$ Hatice ÇíÇEK ${ }^{1 b}$}

${ }^{1}$ Department of

Parasitology, Faculty of Veterinary Medicine, Afyon

Kocatepe University, Afyonkarahisar, Turkey

ORCID-

a0000-0001-6040-761X

b0000-0002-8957-7273

Correspondence

Ahmet GÖKSU

ahmetgoksu@aku.edu.tr

Article info

Submission: 18-02-2021

Accepted: 07-05-2021

Online First: 09-08-2021

e-ISSN: 2548-1150

doi prefix: $10.31797 /$ vetbio

- http://dergipark.org.tr/vetbio

This work is licensed under a Creative Commons Attribution 4.0 International License cc) (7) 
İnsan nüfusunun 2050 yılına kadar tahmini 9 milyar olacağ 1 ve artan nüfusun beslenmesinde g1da üretiminin $\% 50$ oranında artırılmasının gerektiği, bunun ise temiz, sağlıklı ve sürdürülebilir hayvansal gida üretimiyle karşılanabileceği tahmin edilmektedir (Upadhayay vd., 2012; Fitzpatrick, 2013).

Medikal önemi olan protozoonlar Eucoccidia (Cins: Babesia, Theileria, Plasmodium, Cryptosporidium, Eimeria, Toxoplasma) ve Kinetoplastida (Cins: Trypanosoma ve Leishmania) takımlarında yer almaktadır. Günümüzde protozoer enfeksiyonların tedavi ve kontrolünde ilaç kullanımı oldukça yaygındır. Kullanılan ilaçlara karşı oluşan direnç gelişimi aşı çalışmalarına olan ilgiyi artırmıştır. Protozoer enfeksiyonların önlenmesi ve tedavisinde her iki yaklaşımın da tamamlayıcı olduğu kabul edilmektedir (Cerami ve Warren, 1994; Milon, 1994; Tanner ve Evans, 1994).

Hayvancılık sektöründe paraziter hastalıklar açısından önemli sorunlar büyük çiftlik işletmelerinde görülmektedir. $\mathrm{Bu}$ işletmelerde uzun mevsimsel süre boyunca parazitik hastalıkların varlığı, yüksek miktarlarda antiparazitik ilaç kullanımını gerektirmekte bu durum süt, sütten elde edilen ürünler ve ette ilaç kalıntıları ile ilişkili sorunlara yol açmaktadır. Ayrıca, bu tür kemoprofilaksi ve kemoterapinin uzun süreler boyunca pratikte uygulanması zordur (Behr vd., 2016). Uzun süre ilaç kullanımına bağlı gelişen direnç aşıların önleyici etkilerinden faydalanmayı önemli hale getirmiştir (Sharman vd., 2010). Moleküler tekniklerin ilerlemesi, yeni aşıların geliştirilmesini olanaklı hale getirmiştir.

$\mathrm{Bu}$ makalede veteriner protozoolojide kullanılan ve geliştirilmekte olan aşıların mevcut durumunu değerlendirilmiştir.

\section{VETERINER \\ PROTOZOOLOJIDE MEVCUT AŞI UYGULAMALARI}

Günümüzde çoğunluğu serbest yaşayan yaklaşık 65.000 protozoa türünün varlığ1 bildirilmiştir. Hem omurgalı hem de omurgasız hayvanlarda yalnızca 7000 protozoan türü parazit olarak yaşamaktadır (Verma vd., 2012). Protozoan parazitler, hayvanlarda yaygin morbidite ve mortaliteye neden olan önemli etkenlerden biri olarak kabul edilir. Bunların yanında, protozoan parazitlerin çoğu doğada zoonotiktir. Bu nedenle hem ekonomi hem de halk sağlığı açısından yüksek öneme sahiptirler. Theileriosis, babesiosis, toxoplasmosis, coccidiosis, cryptosporidiosis gibi hastalıklar yaygın olarak görülmektedir. Bunlardan Toxoplasmosis ve cryptosporidiosis gibi enfeksiyonlar yaygın görülen zoonozlardandır (Lightowlers, 1994; Meeusen vd., 2007).

Aşılar, ölü, inaktive edilmiş organizmalar veya bunlardan elde edilen saflaştırılmış ürünlerdir. Protozoan enfeksiyonlarına karşı kullanılmakta olan, inaktif, canlı zayıflatılmış, alt ünite, DNA, rekombinant vektör, yenilebilir aşılar gibi çeşitleri bulunmaktadır. Türkiye'de ve dünyada çeşitli etkinliklerde birçok veteriner hekimlik aşıları ruhsatlandırılmıştır. Protozoan enfeksiyonlarına karşı kullanılan lisanslı ticari aşılar ve çeşitleri Tablo 1'de gösterilmiştir.

Çiftlik hayvanlarının protozoan hastalıklarına karşı mevcut olan aşıların büyük kısmı canlı organizmalara dayanmaktadır. Ancak son yıllarda inaktive edilmiş alt ünite aşıların geliştirilmesi ve ticarileştirilmesinde ciddi ilerlemeler kaydedilmiştir (Lightowlers, 1994; Sharman vd., 2010). Hayvanlarda doğal olarak oluşan protozoan hastalıklar için geliştirilen başarılı aşılar, insan aşı araştırmalarına da rehberlik etmektedir (Mcallister, 2014). Parazitler güçlü bir humoral ve hücresel bağışıklık tepkisine neden olurlar. Ancak bu, konağın yeniden enfeksiyona karşı tam korunmasını sağlayamamaktadır. Parazit protozoonlar, yalnızca konağın immün yanıtlarından kaçınmak için değil, aynı zamanda immünokompetan konakta hayatta kalmalarını ve bulaşmalarını kolaylaştırmak için mekanizmalar geliştirmişlerdir. 
Tablo 1. Protozoan enfeksiyonlarına karşı kullanılan lisanslı ticari aşılar ve çeşitleri

\begin{tabular}{|c|c|c|c|c|c|}
\hline Ticari ismi & Üretici & $\begin{array}{c}\text { Hedef } \\
\text { Enfeksiyon }\end{array}$ & Hayvan türü & Aşı tipi & Referanslar \\
\hline Leishmune ${ }^{\circledR}$ & Zoetis, Brezilya & $\begin{array}{l}\text { Leishmaniasis } \\
\text { (L. infantum) }\end{array}$ & Köpek & Alt ünite & $\begin{array}{c}\text { Borja- } \\
\text { Cabrera vd., } \\
2002\end{array}$ \\
\hline Leish-Tec ${ }^{\circledR}$ & $\begin{array}{l}\text { Hertape Calier, } \\
\text { Brezilya }\end{array}$ & $\begin{array}{l}\text { Leishmaniasis } \\
\text { (L. infantum) }\end{array}$ & Köpek & Rekombinant & $\begin{array}{l}\text { Fernandes } \\
\text { vd., } 2008\end{array}$ \\
\hline CaniLeish ${ }^{\circledR}$ & Virbac, Fransa & $\begin{array}{l}\text { Leishmaniasis } \\
\text { (L. infantum) }\end{array}$ & Köpek & $\begin{array}{l}\text { İn vitro aksenik } \\
\text { kültür }\end{array}$ & $\begin{array}{l}\text { Lemesre } \\
\text { vd., } 2005\end{array}$ \\
\hline LetiFend ${ }^{\circledR}$ & $\begin{array}{l}\text { LetiPharma, } \\
\text { İspanya }\end{array}$ & $\begin{array}{l}\text { Leishmaniasis } \\
\text { (L. infantum) }\end{array}$ & Köpek & $\begin{array}{l}\text { Rekombinant } \\
\text { DNA }\end{array}$ & $\begin{array}{l}\text { Cotrina vd., } \\
2018\end{array}$ \\
\hline Coccivac B, D® & $\begin{array}{l}\text { Intervet/Merck } \\
\text { Animal Health }\end{array}$ & $\begin{array}{c}\text { Kanatlı } \\
\text { koksidiyozu }\end{array}$ & $\begin{array}{l}\text { Broyler ve } \\
\text { yumurtacı } \\
\text { tavuklar }\end{array}$ & $\begin{array}{c}\text { Canlı } \\
\text { sporlanmış }\end{array}$ & $\begin{array}{l}\text { Johnson ve } \\
\text { Reid, } 1970\end{array}$ \\
\hline Coccivac-T® & $\begin{array}{l}\text { Intervet /Merck } \\
\text { Animal Health }\end{array}$ & Koksidiyozis & Hindi & $\begin{array}{c}\text { Canlı } \\
\text { sporlanmış }\end{array}$ & $\begin{array}{c}\text { Mathis ve } \\
\text { McDougald, } \\
1989\end{array}$ \\
\hline Nobilis ${ }^{\circledR}$ COX ATM & $\begin{array}{c}\text { Intervet } \\
\text { (Hollanda) }\end{array}$ & Koksidiyozis & Broyler & $\begin{array}{c}\text { Canlı } \\
\text { sporlanmış }\end{array}$ & $\begin{array}{l}\text { Vermeulen } \\
\text { vd., } 2001\end{array}$ \\
\hline $\begin{array}{l}\text { Eimeriavax }{ }^{\circledR} 3 \mathrm{~m}, \mathbf{4 m}, \\
\text { Tamm, Plus }\end{array}$ & $\begin{array}{l}\text { Eimeria Pty, } \\
\text { Avustralya }\end{array}$ & Koksidiyozis & $\begin{array}{c}\text { Broyler, } \\
\text { damızlık ve } \\
\text { yumurtacilarda }\end{array}$ & $\begin{array}{c}\text { Canlı } \\
\text { sporlanmış }\end{array}$ & $\begin{array}{l}\text { Gore vd., } \\
\text { 1983; } \\
\text { Mcdonald } \\
\text { ve Shirley, } \\
2009\end{array}$ \\
\hline Immucox ${ }^{\circledR} C_{1}, C_{2}$ & $\begin{array}{c}\text { Vetech } \\
\text { Laboratories, } \\
\text { Kanada }\end{array}$ & Koksidiyozis & $\begin{array}{c}\text { Broyler ve } \\
\text { damızlık } \\
\text { tavuklarda }\end{array}$ & $\begin{array}{c}\text { Canlı } \\
\text { sporlanmış }\end{array}$ & Lee, 2006 \\
\hline Livacox ${ }^{\circledR} \mathrm{D}, \mathrm{T}, \mathbf{Q}$ & $\begin{array}{l}\text { Biopharm, } \\
\text { Çekya }\end{array}$ & Koksidiyozis & $\begin{array}{c}\text { Broyler ve } \\
\text { damızlık } \\
\text { tavuklarda }\end{array}$ & Canlı atenüe & $\begin{array}{c}\text { Shirley ve } \\
\text { Bedrnik } \\
1997\end{array}$ \\
\hline CoxAbic ${ }^{\circledR}$ & $\begin{array}{l}\text { Novartis AH, } \\
\text { İsviçre }\end{array}$ & Koksidiyozis & $\begin{array}{l}\text { Broyler ve } \\
\text { damızlık }\end{array}$ & Alt ünite & $\begin{array}{l}\text { Mcallister, } \\
\text { 2014; } \\
\text { Wallach, } \\
2002 ; \\
\text { Sharman } \\
\text { vd., } 2010\end{array}$ \\
\hline $\begin{array}{l}\text { Toxovax® } \\
\text { (Yeni Zellanda ve Avrupa) }\end{array}$ & $\begin{array}{l}\text { MSD Animal } \\
\text { Health, ABD }\end{array}$ & $\begin{array}{l}\text { Toxoplasmosis } \\
\quad(T . \text { gondii })\end{array}$ & Koyun & Canlı atenüe & $\begin{array}{l}\text { O’Connell } \\
\text { vd., } 1988\end{array}$ \\
\hline Giardiavax ${ }^{\circledR}$ & Zoetis, Brezilya & $\begin{array}{l}\text { Giardiasis } \\
(\text { G. lamblia })\end{array}$ & Köpek & İnaktive & $\begin{array}{l}\text { Olson vd., } \\
2001\end{array}$ \\
\hline Bovilis ${ }^{\circledR}$ Neoguard & $\begin{array}{c}\text { Intervet } \\
\text { International } \\
\text { B.V., Hollanda }\end{array}$ & $\begin{array}{l}\text { Neosporosis } \\
(\text { N. caninum })\end{array}$ & İnek & İnaktive & $\begin{array}{l}\text { Meeusen } \\
\text { vd., } 2007\end{array}$ \\
\hline Babesia canlı aşıları & $\begin{array}{c}\text { Devlet } \\
\text { tarafindan } \\
\text { finanse edilen } \\
\text { laboratuvarlar, } \\
\text { Avustralya, } \\
\text { Arjantin, Güney } \\
\text { Afrika ve İsrail }\end{array}$ & $\begin{array}{c}\text { Babesiosis ( } B . \\
\text { bovis, } B . \\
\text { bigemina) }\end{array}$ & Sığır & Canlı atenüe & OIE, 2014 \\
\hline $\begin{array}{l}{ }^{1} \text { Tayledoll }{ }^{\circledR},{ }^{2} \text { Teylovac } \AA \text {, } \\
{ }^{3} \text { Rakshavac-T®, }\end{array}$ & $\begin{array}{c}{ }^{1} \text { Dollvet, } \\
\text { Türkiye, }{ }^{2} \text { Vetal, } \\
\text { Türkiye, } \\
{ }^{3} \text { Indian } \\
\text { Immunologicals } \\
\text { Ltd., Hindistan }\end{array}$ & $\begin{array}{l}\text { Tropikal } \\
\text { theileriosis } \\
(\text { T. annulata })\end{array}$ & Sı̆̆ır & $\begin{array}{l}\text { Canlı attenüe } \\
\text { (Theileria } \\
\text { annulata } \\
\text { makroşizontları } \\
\text { ile enfekte } \\
\text { lenfoid hücre) }\end{array}$ & $\begin{array}{l}\text { Altuğ vd., } \\
\text { 2013; Singh } \\
\text { vd., } 2014\end{array}$ \\
\hline Muguga kokteyli & $\begin{array}{c}\text { VetAgro } \\
\text { Tanzania Ltd., } \\
\text { (Kenya ve } \\
\text { Tanzanya) }\end{array}$ & $\begin{array}{c}\text { Şark sahil } \\
\text { humması }(T . \\
\text { parva) }\end{array}$ & Sığır & Canlı virülent & $\begin{array}{l}\text { Patel vd., } \\
2011\end{array}$ \\
\hline
\end{tabular}

Rekombinant DNA teknolojisi ve monoklonal antikorların 1980'lerin başında geliştirilmesiyle, immün (humoral ve/veya hücresel) tepkilerin hedefi olan bireysel antijenler belirlenmiştir. 
Karşılık gelen genleri tanımlamak, klonlamak, dizilemek ve çeşitli patojenik parazitlere karşı olası aşı adayları olmalarını sağlamak için önemli miktarlarda rekombinant veya sentetik antijen üretimi mümkün hale geldiğinden son yıllarda aşı çalışmaları hızla ilerlemektedir (Behr vd., 2016).

\section{Leishmania aşıları}

Leishmaniasisin önlenmesi için farklı aşı türleri geliştirilmiştir (Nagill ve Kaur, 2011). Köpeklerde az sayıda aşı adayı test edilmiş olup dört aşı canine visceral leishmaniasise karşı ticari lisans almıştır. İlki Quil-A® ile adjuvanlanmış yarı saflaştırılmış bir fukozmannoz ligand antijeni (FML) olan Leishmune ${ }^{\circledR}$ aşısıdır. Etkinliği açısından faz III gerekliliklerini karşılamadığı için lisansı 2014 yılından beri askıya alınmıştır (Borja-Cabrera vd., 2002). Leish-Tec $\AA$ ise saponin ile adjuvanlanmış bir rekombinant protein A2 içeren Brezilya'da satılan ticari bir aşıdır. Avrupa'da kullanılan (CaniLeish ${ }^{\circledR}$, Virbac, France) aşısı ise, L. infantum sekret/ekstret ürünlerinden (LiESAp) oluşur ve QA-21 ile adjuvanlanır ve son olarak, aktif bileşen olarak Protein Q içeren LetiFend $\AA$, Avrupa Komisyonundan pazarlama izni almıştır (Cotrina vd., 2018; Fernandes vd., 2008; Lemesre vd., 2005; Lemesre vd., 2007).

\section{Antikoksidiyal aşıllar}

Eimeria türlerinin canlı ookistleri aşı üretimi için kullanılan kanatlıların dışkılarından elde edilir. Kanatlı çiftliklerinde, koruyucu bağışıklığ sağlamak için yavruların karışık türlerdeki koksidiyal ookistlerle ağızdan aşılanması tekniği kullanılır. Günümüzde, canlı koksidiyoz aşılarının antikoksidiyal ilaçlar kullanımından önce uygulanması önerilmektedir (Williams, 2002).

\section{Coccivac ${ }^{\circledR}-B$}

Bu canlı ve zayıflatılmış aşı, ilk olarak 1940'ların sonlarında, mevcut antikoksidiyal ürünler piyasaya sürülmeden önce geliştirilen izolatlardan üretimiştir. Eimeria acervulina, E. mivati, E. maxima ve E. tenella suşlarından hazırlanmıştır. Coccivac B aşısı, mevcut antikoksidiyallerin performansını eski haline getirmek için değerli bir aşıdır. Kanatlılar üzerinde yapılan deneysel bir çalışmada, bu aşı beş farklı E. tenella suşu ile çeşitli koruma seviyeleri göstermiştir (Chapman, 1994; Williams vd., 2000; Awad vd., 2013).

\section{CoxAbic ${ }^{\circledR}$}

Kümes hayvanları için ticari olarak temin edilebilen ilk alt ünite aşıdır ve E. maxima'nın makrogametositinden izole edilmiş saflaştırılmış antijenlerini içermektedir. Gametosit antijeni kullanılarak yapılan aşılama, antikor yanıtının üretilmesine neden olmaktadır. CoxAbic $\AA$, doz başına diğer koksidiyoz aşı türlerine göre daha pahalı olmasına rağmen aşılanan her tavuk, çok sayıda yavruya bağışıklığı geçirmektedir (Mcallister, 2014; Sharman vd., 2010; Wallach, 2002).

\section{Livacox ${ }^{\circledR} \mathrm{D}, \mathrm{T}, \mathbf{Q}$}

Evcil kanatlılar için geliştirilen canlı atenüe koksidiyoz aşılarıdır. Yumurtacılar için Livacox ${ }^{\circledR} \quad$ D, broylerler için Livacox ${ }^{\circledR} T$, damızlık ve yumurtacı yarkalar için Livacox ${ }^{\circledR} \mathrm{Q}$ kullanılmaktadır (Shirley ve Bedrnik 1997).

\section{$\operatorname{Paracox}{ }^{\circledR}-8$}

Ookist süspansiyonundan oluşan canlı zayıflatılmış oral bir aşıdır. Tavukların farklı Eimeria türlerine karşı aktif immünizasyonu için kullanılır (Shirley vd., 2005).

\section{Immucox ${ }^{\circledR} \mathrm{C} 1, \mathrm{C} 2$}

Oral yolla uygulanan Eimeria spp. canlı ookist aşısı, sağlıklı broylerlerde koksidiyozise karşı bağışıklık geliştirmelerine yardımcı olmak için tasarlanmıştır. Kanatlı hayvanlara üretim süreçleri boyunca tek sefer uygulanarak koruyucu bağışıklık sağlayan bir aşıdır (Lee, 2006). 


\section{Eimeriavax ${ }^{\circledR}(3 \mathrm{~m}, 4 \mathrm{~m}$, Tamm, plus $)$}

$\mathrm{Bu}$ aşı, PBS içinde süspanse edilmiş E.acervulina suşu RA, E. maxima suşu MCK + 10, E. necatrix suşu mednec $3+8$ ve E. tenella suşu Rt3 + 15'in canl1 ookistlerinden oluşur (Gore vd., 1983; Mcdonald ve Shirley, 2009).

\section{Nobilis ${ }^{\circledR}$ COX ATM}

İyonofor bileşiklerin varlığında bile benzersiz bir aktif olma özelliğine sahip canlı bir aşıdır. Aşı, iyonofor bileşiğe toleranslı E. acervulina, E. tenella ve E. maxima suşlarını içerir. Bu aşının en önemli avantajlarından biri, bağışıklık üretiminin yanı sıra, bağışıklığın zayıf olduğu 34 haftalık yaşlarda bile iyonofor bileşiklerinin kullanımına izin vermesidir (Vermeulen vd., 2001).

\section{Coccivac-T®}

Eimeria dispersa, E. meleagrimitis, E. adenoides ve E. gallopavonis'in sporlanmış ookistlerini içeren canlı bir aşıdır. Günlük hindi palazlarına sprey şeklinde uygulanır. Coccivac T'deki Eimeria suşları, modern iyonofor ve kimyasal antikoksidiyal ürünlerin ortak kullanımından önce izole edilmiş ve tüm antikoksidiyallere karş1 oldukça hassas olduğu belirtilmiştir (Mathis ve McDougald, 1989).

\section{Coccivac-D®}

Farklı Eimeria türlerini içeren canlı, sporlanmış bir ookist aşısıdır. Tam bağışıklık sağlamak için, orijinal koksidiyal ookist dozu sürüde en az dört yaşam döngüsünü tamamlamalıdır (Johnson ve Reid, 1970).

\section{Koksidiyozis aşı adayları}

Eimeria acervulina'nın rekombine edilmiş bir merozoit antijeni olan p250 hastalığa karşı \%50 koruma sağlamaktadır (Kim vd., 1989). MZ5-7 ise Eimeria tenella MZ5-7 ve tavuk IL-17 genini birlikte eksprese eden bir DNA aşısıdır. MZ5-7 geni, 2. nesil merozoitin yüzey proteini MZP57'yi kodlar. MZ5-7, aşı için etkili bir aday antijendir ve sitokinin antijen ile birlikte ekspresyonu, DNA aşısını güçlendirmek için alternatif bir yöntemdir (Xu ve Li, 2011).

\section{pcDNA-Gam56}

pcDNA-Gam56 ile aşılanmış gruplar, yüksek lenfosit proliferasyonu ve antikor seviyeleri gösterirken aynı zamanda vücut ağırlığında artış ve büyük oranda ookist saç1lımının azalması (\%53,7) görülmüştür (Xu vd., 2013).

\section{TA4}

İnterlökin-2 ile birlikte eksprese edilen $E$. tenella'ya karşı geliştirilen bir DNA aşısıdır. Eimeria tenella, E. necatrix, E. maxima ve E. acervulina'ya karşı koruyucu bağışıklık oluşturabilir. Bulgular, yapılandırılmış multivalent epitop DNA aşılarının, Eimeria türlerinin meydana getirdiği enfeksiyonlara karşı potansiyel multivalent aday aşılarından biri olduğunu göstermektedir (Song vd., 2015).

\section{EtMIC2}

Bitkinin eksprese ettiği rekombinant EtMIC2'nin hem humoral hem de hücre aracılı immün yanıtları ortaya çıarma yeteneğinden faydalanılmıştır. EtMIC2 uygulanan kanatlılarda karşılaştırıldığında, azalmış ookist çıkışı ve artan kilo artışı gösterilmiştir (Sathish vd., 2011).

Ayrıca Eimeria türlerine karşı başarıyla test edilmekte olan antikoksidiyal alt ünite aş1 adayları şunlardır; Apikal membran antijeni 1, mikronem proteini 2-3, bağışıklık haritalanmış protein 1, laktat dehidrogenaz, rhomboid benzeri proteinler, SO7 (Mehlhorn, 2016).

\section{Toxoplasma gondii aşıları}

\section{S48 suşu (Toxovax®)}

Farelerde (x3000) tekrarlanan pasajlarla üretilir. Parazitin bradizoit veya ookist formların oluşumunu engellemektedir. Abort ve yenidoğan ölümlerini \%75 oranında azalttığı bildirilmiştir (O’Connell vd., 1988). 


\section{TS-4 ve T-263}

Sicaklığa duyarlı bir suş olan TS-4, kist oluşumuna ve konjenital toksoplazmoza karşı koruma sağlamaktadır (Bourguin vd., 1993). T263 ise Toxoplasma gondii'nin ookist oluşturmayan, canlı mutant bradizoitidir. T263'ün uygulanması, kedilerde ookist saçılımının azalmasını sağlayarak koruyucu etki oluşturur (Verma ve Khanna, 2013). Toksoplazmozise karşı aşı geliştirmek amacıyla gen düzenlemesine dayalı canlı zayıflatılmış, nanopartikül, ekzozom ve karbonhidrat bazlı aşıların geliştirildiği teknikler ve uygulamalar son yıllarda kullanılmaya başlanmıştır (Wang vd., 2019).

\section{Giardia aşıları}

\section{Giardiavax ${ }^{\circledR}$}

Köpekler için hazırlanmış, kültür yöntemiyle elde edilen bir trofozoit aşısı olup, G. lamblia enfeksiyonunun ve saçılmasının önlenmesinde etkili bulunmuştur. Aşı, koyunlardan izole edilen G. duodenalis'ten elde edilmiştir. Deri altına 1 $\mathrm{mL}$ dozunda uygulanır. İlk doz 8 haftalıkken ve ikinci doz ise ilk uygulamadan 2-4 hafta sonra verilir. Ardından aşı her yıl tekrarlanır (Olson vd., 2001). Başka bir çalışmada zayıflatılmış Salmonella typhimurium tarafından taşınan $\alpha 1$ Giardin ve CWP2'nin bivalent DNA aşısı kullanılarak Giardia lamblia ile enfekte olmuş farelerin aşılanması sonucunda, dışkıdaki trofozoitlerin ve kistlerin azaldığı tespit edilmiştir (Feng vd., 2016).

\section{Neospora caninum aşılları}

İdeal bir aşının hem enfeksiyona hem de klinik belirtilere karşı koruma sağlaması gerekir, bu nedenle, fötusa zararı olmayan hücre aracılı bağışıklık tepkisini oluşturabilecek bir aşıya ihtiyaç vardır (Goodswen vd., 2013). Neospora caninum'a karşı geliştirilen öldürülmüş taşizoit bazlı aşının, süt sığırlarında abortusun önlenmesinde etkili olduğu bildirilmiştir (Weston vd., 2012; Williams vd., 2007). Tutunmada, istila etmede veya diğer parazit- konak-hücre etkileşimi süreçlerinde önemli role sahip olan proteinler, bu önemli protozoan parazite karşı etkili bir aşı geliştirilmesi için uygun hedeflerdir. Neospora enfeksiyonuna karşı bu şekilde koruma sağlanabileceği bildirilmiştir (Hemphill vd., 2013). Sığır neosporosisine karşı küresel aşı pazarının çok büyük olduğu öne sürülse de henüz aborta neden olan neosporosisin bulaşmasını önleyecek derecede etkili bir tedavi veya aşı bulunmamaktadır (Weston vd., 2012).

\section{Bovilis ${ }^{\circledR}$ Neoguard}

Tek lisanslı $N$. caninum aşısı, inaktive edilmiş $N$. caninum taşizoitleri, \%10 havlogen adjuvant1, $\% 5$ stabilizörler ve $\% 5$ fosfat tamponlu salinden oluşan (Bovilis ${ }^{\circledR} \quad$ Neoguard Intervet International B.V., Hollanda) aşısıdır. Abort oranlarını \%50'ye kadar düşürmekle beraber 1 yıla kadar koruyuculuk sağlayabilmektedir (Romero vd., 2004; Weston vd., 2012). Son zamanlarda, soya lesitin / b-glukan adjuvantı (sNcAg/AVEC) ile taşizoit özütü aşısının çözünür bir fraksiyonu, gebe sığırlarda immünojeniklik ve yüksek IFN- $\gamma$ tepkilerinin indüksiyonunu gösterdiği bildirilmiştir (Mansilla vd., 2015).

\section{Canlı taşizoit aşıları}

Nc-Nowra, Nc-Spain1H ve Arjantin izolatı Nc-6 gibi doğal olarak zayıflatılmış veya virülensi daha düşük izolatlardan oluşan canlı taşizoit aşıları, $N$. caninum antikor yanıtlarında önemli bir artış sağlamakta ve abort oranlarını önemli ölçüde düşürmektedir. Bununla birlikte, canlı aşıların kullanılmasının, canlı parazitlerin toplu olarak korunması ve aşılamadan sonra patojenliğin tersine dönme riski gibi bazı doğal dezavantajları vardır. $\mathrm{Bu}$ nedenle etkisizleştirilmiş veya alt ünite aşıların daha uygun seçenekler olduğu düşünülmektedir (Hecker vd., 2013; Reichel vd., 2015). Ayrica, oligo-mannoz mikrozomunda (M3-NcGRA7) hapsolmuş rekombinant NcGRA7 (50-200 lg) ve rNcSAG1, rNcHSP20 ve rNcGRA7 dâhil olmak üzere bakteriyel olarak eksprese edilen ve 
saflaştırılmış rekombinant proteinler, enfeksiyonu önleyemedikleri için çok az umut vadetmektedir. Bu nedenle, Neospora'nın canlı zayıflatılmış suşları (Ca2+-bağımlı protein kinaz 2 eksik taşizoitler dâhil) gibi yeni, daha verimli bir aşı yaklaşımının tanımlanması, neosporosise karşı uzun süreli koruma sağlamak için kritik görülmektedir (Nishimura vd., 2013; Wang vd., 2018).

\section{Babesia aşılları}

Pirodog ${ }^{\circledR} /$ Nobivac ${ }^{\circledR}$ Piro: İn vitro kültürlerin (B. canis ve $B$. rossi) süpernatantlarının $\% 80$ koruma sağlayan çözünebilir parazit antijenidir (Schetters, 2005). Köpeklere 6 aylıkken verilir ve ilk aşılamadan 3 ila 6 hafta sonra ve daha sonra ise kas içi yolla 6 ayda bir yeniden aşılama gereklidir. Her iki aşı da enjeksiyon bölgesinde bir miktar lokal reaksiyon oluşturur ancak bu reaksiyon Nobivac ${ }^{\circledR}$ Piro aşısı kullanımında daha fazladir (Freyburger vd., 2011). Aşı Avrupa'nın bazı bölgelerinde pazarlanmıştır fakat aşının artık üretilmediği bildirilmiştir (Mcallister, 2014).

Sığırlarda Babesia bovis ve B. bigemina'nın canlı zayıflatılmış suşlarından oluşan aşılar, birçok ülkede enfekte olmuş donör hayvanların kanlarından veya in vitro kültür yoluyla üretilmektedir. $\mathrm{Bu}$ aşılar hayvanlar enfekte kenelerin bulunmadığ 1 bir bölgeden kene ile enfekte olmuş bir alana taşındığında önerilmektedir. Zayıflatılmış B. bovis etkenleri, splenektomize edilmiş öküzlerde virülans bir suşun 20 ile 30 arasında seri ve hızlı geçişlerinden üretilir. B. bigemina'nın zayıflatılması benzer bir prosedürle yapılır, fakat bu durumda buzağılar arasında yavaş ve art arda geçişler kullanılır (Florin-Christensen vd., 2014).

Babesia bovis ve B. bigemina canlı aşılarının çoğu, özellikle Avustralya, Arjantin, Güney Afrika ve İsrail'de hayvancilık endüstrilerine hizmet olarak devlet destekli üretim tesislerinde üretilmektedir. $\mathrm{Bu}$ iki parazitin her biri tarafından enfekte olan eritrositlerin karıştırıldı ğ bivalent bir formül olarak veya trivalent bir formül olarak hazırlanmaktadır (OIE, 2014).

Canlı aşılar genellikle 4-10 aylık buzağılara güvenli uygulanırken bazen yaşlı hayvanların aşılanması sonrasında klinik hastalık gelişebilmektedir. Bundan dolayı hayvanlar belli bir süre gözetim altında tutulmalı ve yan etkiler gözlenirse antiprotozoer bir ilaçla tedavi edilmelidir. Normalde ömür boyu süren koruyucu bağışıklık 3-4 hafta içinde gelişmektedir (De Waal ve Combrink 2006). Mevcut aşıların klinik sığır babesiosis vakalarını önlemedeki genel etkinliğine rağmen, hastalığa karşı koruma sağlayan, daha güvenli, kullanımı ve üretimi daha kolay olan gelişmiş alt ünite aşılarının geliştirilmesine önemli derecede ihtiyaç vardır (Ganzinelli vd., 2018).

Şimdiye kadar, herhangi bir alt ünite aşısı ruminantlardaki Babesia türlerinde doğal konakçılara koruyucu bağışıklık kazandırmada başarılı olamamıştır. Yine de patojenite mekanizmaları ve konak-patojen etkileşimlerini ifade eden moleküller dahil olmak üzere bu ve ilgili parazitler hakkında hızla artan bilgi düzeyi göz önüne alındığında, alt ünite aşılarında istenen seviyelere çok kısa süre içerisinde ulaşılabilir (Florin-Christensen vd., 2014). Ayrıca kene önleyici aşılar bu tip aşılara göre daha uygun fiyatlı ve çevre dostu bir çözüm sunmaktadır. Kene kontrolü ve aşılamayı içeren uyumlu önlemler ve bu hastalıklara dirençli çiftlik hayvanlarının kullanımı, hastalıkların önlenmesinde muhtemelen en doğru sonuçları üretecektir (Ganzinelli vd., 2018). Babesia enfeksiyonlarından korunma amaciyla geliştirilmekte olan aşı adayları Tablo 2'de sunulmuştur.

\section{Theileria aşıları}

Theileria parva ve T. annulata için canlı aşılar 40 yıldan fazla bir süre önce üretilmiştir. Birçok alanda kullanımlarını sinırlandıran dezavantajları bulunmaktadır (Nene vd., 2016; Radley vd., 1975). Theileria türleri, sığır makrofajları veya lenfoid hücreleri içinde in 
vitro kültüre adapte edilebilir. Pek çok suş, hücre kültüründe uzun süreli bir geçişle zayiflatılabilmektedir (Gubbels vd. 2000). Aşının koruyucu etkisinin, sahada en az 19 ay sürdüğü bildirilmiştir. Aşı etkinliğinin süresinin, enfekte kenelere tekrar tekrar maruz kalmaya bağlı olup olmadığı sorgulanmalıdır (Yin vd., 2008). Theileria lestoquardi (Theileria hirci) için benzer aşılar, koyunlarda enfeksiyondan korunmak için İran, Irak ve Bulgaristan'da kullanılmaktadır (Ali vd., 2008).

Tablo 2. Babesia enfeksiyonlarından korunma amacıyla geliştirilmekte olan aşı adayları

\begin{tabular}{|lccc|}
\hline Așı Adayları & Aşı tipi & Hedef Türler & Referanslar \\
\hline GASA-1 & Alt ünite & Babesia bovis & (Flores vd., 2020) \\
\hline Canine Babesiosis Antigen (CBA) & Rekombinant & Babesia canis & (Moubri vd., 2018) \\
\hline GPI bağlı proteinler & Rekombinant & $\begin{array}{c}\text { Babesia microti, } \\
\text { Babesia divergens }\end{array}$ & (Wieser vd., 2019) \\
\hline 6-Cys genleri & Canlı aşı & Babesia bovis & (Alzan vd., 2019) \\
\hline
\end{tabular}

\section{Theileria annulata şizont aşısı}

Tarım ve Orman Bakanlığı Pendik Veteriner Kontrol Araştırma Enstitüsü tarafindan ve bazı özel firmalar tarafından üretilen atenüe $T$. annulata şizont aşısı 1982 yılından bu yana ülkemizde üretilmekte ve sahada uygulanmaktadır (Altuğ vd., 2013; Özkoc ve Pipano, 1981). Hindistan'da ise aynı tekniklerle üretilen uzun süreli in vitro pasajlarla zayıflatılmış, lenfoblast hücre kültüründe üretilen canlı şizontları içeren (Rakshavac-T®, Indian Immunologicals Ltd., India) aş1 kullanılmaktadır (Singh vd., 2014).

\section{SPAG-1 ve p67}

Theileria annulata ve Theileria parva'nın her ikisi de yaşam döngüsünün sporozoit aşamasında sırasıyla SPAG-1 ve p67 olarak adlandırılan ana yüzey antijenine sahiptir. Her durumda, bu antijenler aşı adaylarıdır. Daha önceki çalışmalarda bir derece homolog korumayı indükledikleri bildirilmiştir (Hall vd., 2000).

\section{Tams1}

İyi karakterize edilmiş bir T. annulata antijeni olan Tams1, bugüne kadar çalışılan tüm Theileria türleri üzerinde tanımlanmış olan ana merozoit piroplazma yüzey antijeni (mMPSA) ailesinin bir üyesidir (Katzer vd., 2002). Aşının, klinik olarak önemli herhangi bir anormallik veya yan etki olmaksızın sığırlarda enfeksiyonun önlenmesinde etkili olduğu kanıtlanmıştır (Esmaelizad vd., 2011).

\section{Muguga kokteyli}

Theileria parva'ya karşı Doğu Afrika Veteriner Araştırma Örgütü (şimdiki ismiyle Kenya Tarım Araştırma Enstitüsü) tarafindan geliştirilen multivalent bir aşı olan Muguga kokteyli Kenya ve Tanzanya'da kullanılması için lisans almıştır (Patel vd., 2011).

\section{Cryptosporidiosis aşıları}

\section{Liyofilize C. parvum ookisti}

Liyofilize ookistlerle oral olarak aşılama sonrasında, ortalama diyare ve ookist çıkarma sürelerinde kısalma saptanmıştır (Harp ve Golf, 1995).

\section{Aşı adayları}

Cryptosporidiosis enfeksiyonundan korunmada sporozoitlerin yüzeyinde bulunan, Gp15, Gp40 ve Gp900 ve düşük karmaşıklıkta asidik proteine (Cp23) sahip glikoproteinler mevcut aş1 adaylarıdır (Haserick vd., 2017). 


\section{Cpgp40/15 ve Cpgp40}

Cpgp40/15'in İndirekt immünofloresans analizi ile hücre içi gelişim sırasında parazitofor vakuol membranı (PVM) ile ilişkili olduğu gösterilmiştir. Bu antijen gruplarına karşı gelişen anti-gp40/15 ve anti-gp40 antikorları, in vitro olarak $C$. parvum enfeksiyonunu nötralize etme yeteneği gösterdiğgi bildirilmiştir. Konağın istilasında veya PVM'de Cpgp40/15'in (veya gp40/15 kompleksinin) spesifik rolünü ve fonksiyonel mekanizmasını tam olarak anlamak ve gp40/gp15'in cryptosporidiosis için bir aş1 adayı olarak uygulanabilirliğini belirlemek için daha fazla araştırma gerekmektedir (Cui vd., 2020).

İnaktive edilmiş, zayıflatılmış ve canlı tam hücre aşıları, günümüzün geleneksel aşı sistemlerinin bir parçasıdır. $\mathrm{Bu}$ tam hücre aşılarıyla karşılaştırıldığında, aşı geliştirmede çoklu epitop tabanlı araştırma yaklaşımları önem kazanmaktadır. Cryptosporidium parvum'a karşı çoklu alt ünite aşı tasarımı için immünoinformatik çalışmalar devam etmektedir (Dhal vd., 2019).

\section{SONUC}

Aşılama, dünya çapında halk sağlığı üzerinde oldukça büyük bir etkisi olan etkili bir tıbbi müdahale olarak kendini kanıtlamıştır. Evcil hayvanların sağlığı ve üretkenliği, dünya çapında protozoanların neden olduğu paraziter hastalıklarla önemli derecede etkilenmektedir. Ayrıca birçok durumda zoonoz olan bu parazitler insan sağlığını da etkilemektedir. Hayvanlarda ilaca dirençli parazitlerin yaygın olarak görülmesi, paraziter hastalıkların kontrolünü tehdit etmektedir. Aşılama aynı zamanda halk sağlığını iyileştirmeyi de hedeflediğinden ucuz ve etkili bir aşının geliştirilmesi önem arz etmektedir. Ekonomik olarak uygun ve etkili protozoan aşıları geliştirme çabaları, yeni aşı adayları olabilecek yeni antijenleri keşfetme stratejileri hala devam etmektedir. Yakın gelecekte, veteriner sağlik hizmetlerinde hayvanların paraziter hastalıklarına karşı geliştirilecek yeni aşıların kullanımının, hayvancılık verimliliğinin artırılmasına önemli katkı sağlaması beklenmektedir. Ayrıca bu alanda gerçekleşen ilerlemeler insanlar için yapılan aşı geliştirme çalışmaları için de yol gösterici olacaktır. Sonuç olarak, gelecekte paraziter hastalıklara karşı aşılamanın parazitik enfeksiyonların kontrolünde en iyi alternatiflerden biri olacağı öngörülmektedir.

\section{TEȘEKKÜR / ACIKLAMALAR}

Çıkar çatışması: Yazarlar herhangi bir çıkar çatışması olmadığını bildirmişlerdir.

\section{KAYNAKLAR}

Ali, A. M., Beyer, D., Bakheit, M. A., Kullmann, B., Salih, D. A., Ahmed, J. S., \& Seitzer, U. (2008). Influence of subculturing on gene expression in a Theileria lestoquardi-infected cell line. Vaccine, 26, G17-G23.

Altuğ, N., Özdemir, R., \& Cantekin, Z. (2013). Ruminantlarda koruyucu hekimlik: I. aşı uygulamaları. Erciyes Üniversitesi Veteriner Fakültesi Dergisi, 10(1), 33-44.

Alzan, H. F., Cooke, B. M., \& Suarez, C. E. (2019). Transgenic Babesia bovis lacking 6-Cys sexual-stage genes as the foundation for non-transmissible live vaccines against bovine babesiosis. Ticks and tickborne diseases, 10(3), 722-728.

Awad, A. M., El-Nahas, A. F., \& Abu-Akkada, S. S. (2013). Evaluation of the protective efficacy of the anticoccidial vaccine Coccivac-B in broilers, when challenged with Egyptian field isolates of $E$. tenella. Parasitology research, 112(1), 113-121.

Behr, C., da Silva, L.H.P. (2016). Vaccination Against Protozoa. In H. Mehlhorn (Eds), Encyclopedia of Parasitology. Springer, Berlin, Heidelberg. https://doi.org/10.1007/978-3-662-43978-4_3357.

Borja-Cabrera, G. P., Pontes, N. C., Da Silva, V. O., De Souza, E. P., Santos, W. R., Gomes, E. M., \& De Sousa, C. P. (2002). Long lasting protection against canine kala-azar using the FML-QuilA saponin vaccine in an endemic area of Brazil (Sao Goncalo do Amarante, RN). Vaccine, 20(27-28), 3277-3284.

Bourguin, I., Chardès, T., \& Bout, D. (1993). Oral immunization with Toxoplasma gondii antigens in association with cholera toxin induces enhanced protective and cell-mediated immunity in C57BL/6 mice. Infection and immunity, 61(5), 2082-2088.

Cerami, A., \& Warren, K. S. (1994). Drugs. Parasitology Today, 10(10), 404-406.

Chapman, H. D. (1994). Vaccination with Coccivac-B renews sensitivity of coccidial population to salinomycin university of Arkansas. Poultry Science, 73, 476-478. 
Cotrina, J. F., Iniesta, V., Monroy, I., Baz, V., Hugnet, C., Marañon, F., \& Alonso, C. (2018). A large-scale field randomized trial demonstrates safety and efficacy of the vaccine LetiFend $\AA$ against canine leishmaniosis. Vaccine, 36(15), 1972-1982.

Cui, Z., Wang, L., Wang, Y., Li, J., Wang, R., Sun, M., \& Zhang, L. (2020). Cryptosporidium parvum gp40/15 Is Associated with the Parasitophorous Vacuole Membrane and Is a Potential Vaccine Target. Microorganisms, 8(3), 363.

De Waal, D. T., \& Combrink, M. P. (2006). Live vaccines against bovine babesiosis. Veterinary parasitology, 138(1-2), 88-96.

Dhal, A. K., Pani, A., Mahapatra, R. K., \& Yun, S. I. (2019). An immunoinformatics approach for design and validation of multi-subunit vaccine against Cryptosporidium parvum. Immunobiology, 224(6), 747-757.

Esmaelizad, M., Niaraki, S. J., \& Fesharaki, R. H. (2011). Molecular and phylogenetic analysis of the partial tams1 gene sequence of a vaccine strain of Theileria annulata. Brazilian Archives of Biology and Technology, 54(6), 1109-1116.

Feng, X. M., Zheng, W. Y., Zhang, H. M., Shi, W. Y., Li, Y., Cui, B. J., \& Wang, H. Y. (2016). Vaccination with bivalent DNA vaccine of $\alpha 1$-Giardin and CWP2 delivered by attenuated Salmonella typhimurium reduces trophozoites and cysts in the feces of mice infected with Giardia lamblia. PloS one, 11(6), e0157872.

Fernandes, A. P., Costa, M. M. S., Coelho, E. A. F., Michalick, M. S. M., de Freitas, E., Melo, M. N., \& Gazzinelli, R. T. (2008). Protective immunity against challenge with Leishmania (Leishmania) chagasi in beagle dogs vaccinated with recombinant A2 protein. Vaccine, 26(46), 5888-5895.

Fitzpatrick, J. L. (2013). Global food security: the impact of veterinary parasites and parasitologists. Veterinary parasitology, 195(3-4), 233-248.

Flores, D. A., Rodriguez, A. E., Tomazic, M. L., de Echaide, S. T., Echaide, I., Zamorano, P., \& FlorinChristensen, M. (2020). Characterization of GASA-1, a new vaccine candidate antigen of Babesia bovis. Veterinary Parasitology, 287, 109275.

Florin-Christensen, M., Suarez, C. E., Rodriguez, A. E., Flores, D. A., \& Schnittger, L. (2014). Vaccines against bovine babesiosis: where we are now and possible roads ahead. Parasitology, 141(12), 15631592.

Freyburger, L., Lemaitre, L., Medaille, C., Oberli, F., Fanchon, L., \& Bergamo, P. (2011). Comparative safety study of two commercialised vaccines against canine babesiosis induced by Babesia canis. Parasite (Paris, France), 18(4), 311-318.

Ganzinelli, S., Rodriguez, A., Schnittger, L., \& FlorinChristensen, M. (2018). Babesia in Domestic Ruminants. In Parasitic Protozoa of Farm Animals and Pets (pp. 215-239). Springer, Cham.

Goodswen, S. J., Kennedy, P. J., \& Ellis, J. T. (2013). A review of the infection, genetics, and evolution of Neospora caninum: from the past to the present. Infection, Genetics and Evolution, 13, 133150.
Gore, T., Long, P., Kogut, M., \& Johnson, J. (1983). Attenuation of Eimeria necatrix and E. tenella of U. S. Origin by Serial Embryo Passage. Avian Diseases, 27(3), 569-576. doi:10.2307/1590298

Gubbels, M. J., Viseras, J., Habela, M. A., \& Jongejan, F. (2000). Characterization of attenuated Theileria annulata vaccines from Spain and the Sudan. Annals of the New York Academy of Sciences, 916(1), 521-532.

Hall, R., R. boulter, N., Brown, C. D., Wilkie, G., Kirvar, E., Nene, V., \& Morzaria, S. P. (2000). Reciprocal cross-protection induced by sporozoite antigens SPAG-1 from Theileria annulata and p67 from Theileria parva. Parasite Immunology, 22(5), 223-230.

Harp, J. A., \& Goff, J. P. (1995). Protection of calves with a vaccine against Cryptosporidium parvum. The Journal of parasitology, 54-57.

Haserick, J. R., Klein, J. A., Costello, C. E., \& Samuelson, J. (2017). Cryptosporidium parvum vaccine candidates are incompletely modified with $\mathrm{O}$ linked-N-acetylgalactosamine or contain N-terminal $\mathrm{N}$-myristate and S-palmitate. PloS one, 12(8), e0182395.

Hecker, Y. P., Moore, D. P., Quattrocchi, V., RegidorCerrillo, J., Verna, A., Leunda, M. R., \& Campero, C. M. (2013). Immune response and protection provided by live tachyzoites and native antigens from the NC-6 Argentina strain of Neospora caninum in pregnant heifers. Veterinary parasitology, 197(3-4), 436-446.

Hemphill, A., Debache, K., Monney, T., Schorer, M., Guionaud, C., Alaeddine, F., \& Mueller, J. (2013). Proteins mediating the Neospora caninum-host cell interaction as targets for vaccination. Frontiers in Bioscience (Elite Ed), 5, 23-36.

Johnson, J., \& Reid, W. M. (1970). Anticoccidial drugs: lesion scoring techniques in battery and floor-pen experiments with chickens. Experimental parasitology, 28(1), 30-36.

Katzer, F., McKellar, S., Ferguson, M. A., d'Oliveira, C., \& Shiels, B. R. (2002). A role for tertiary structure in the generation of antigenic diversity and molecular association of the Tams1 polypeptide in Theileria annulata. Molecular and biochemical parasitology, 122(1), 55-67.

Kim, K. S., Jenkins, M. C., \& Lillehoj, H. S. (1989). Immunization of chickens with live Escherichia coli expressing Eimeria acervulina merozoite recombinant antigen induces partial protection against coccidiosis. Infection and immunity, 57(8), 2434-2440. doi: 10.1128/IAI.57.8.2434-2440.1989.

Lee, E. H. (2006). Combination of vaccination and medication in the same crop for the control of coccidiosis in chickens and turkeys. International Poultry Production, 14(5), 23.

Lemesre, J. L., Holzmuller, P., Cavaleyra, M., Gonçalves, R. B., Hottin, G., \& Papierok, G. (2005). Protection against experimental visceral leishmaniasis infection in dogs immunized with purified excreted secreted antigens of Leishmania infantum promastigotes. Vaccine, 23(22), 2825-2840. 
Lemesre, J. L., Holzmuller, P., Gonçalves, R. B., Bourdoiseau, G., Hugnet, C., Cavaleyra, M., \& Papierok, G. (2007). Long-lasting protection against canine visceral leishmaniasis using the LiESAp-MDP vaccine in endemic areas of France: double-blind randomised efficacy field trial. Vaccine, 25(21), 42234234.

Lightowlers, M. W. (1994). Vaccination against animal parasites. Veterinary Parasitology, 54(1-3), 177-204.

Mansilla, F. C., Moore, D. P., Quintana, M. E., Cardoso, N., Hecker, Y. P., Gual, I., \& Capozzo, A. V. (2015). Safety and immunogenicity of a soluble native Neospora caninum tachyzoite-extract vaccine formulated with a soy lecithin/ $\beta$-glucan adjuvant in pregnant cattle. Veterinary immunology and immunopathology, 165(1-2), 75-80.

Mathis, G. F., \& McDougald, L. R. (1989). Restoration of drug sensitivity on turkey farms after introduction of sensitive coccidia during controlled-exposure immunization. Colloques de l'INRA (France).

Mcallister, M. M. (2014). Successful vaccines for naturally occurring protozoal diseases of animals should guide human vaccine research. A review of protozoal vaccines and their designs. Parasitology, 141(5), 624-640.

McDonald, V., \& Shirley, M. W. (2009). Past and future: vaccination against Eimeria. Parasitology, 136(12), 1477-1489.

Meeusen, E. N., Walker, J., Peters, A., Pastoret, P. P., \& Jungersen, G. (2007). Current status of veterinary vaccines. Clinical microbiology reviews, 20(3), 489510.

Mehlhorn H. (2016). Vaccine Anticoccidials. In $\mathrm{H}$. Mehlhorn (Eds), Encyclopedia of Parasitology. Springer, Berlin, Heidelberg. https://doi.org/10.1007/978-3-662-43978-4_4362.

Milon, G. (1994). Drugs or vaccines? Parasitology Today, 10, 402-403.

Moubri, K., Kleuskens, J., Van de Crommert, J., Scholtes, N., Van Kasteren, T., Delbecq, S., \& Schetters, T. (2018). Discovery of a recombinant Babesia canis supernatant antigen that protects dogs against virulent challenge infection. Veterinary parasitology, 249, 21-29.

Nagill, R., \& Kaur, S. (2011). Vaccine candidates for leishmaniasis: a review. International immunopharmacology, 11(10), 1464-1488.

Nene, V., Kiara, H., Lacasta, A., Pelle, R., Svitek, N., \& Steinaa, L. (2016). The biology of Theileria parva and control of East Coast fever-current status and future trends. Ticks and tick-borne diseases, 7(4), 549-564.

Nishimura, M., Kohara, J., Kuroda, Y., Hiasa, J., Tanaka, S., Muroi, Y., \& Nishikawa, Y. (2013). Oligomannose-coated liposome-entrapped dense granule protein 7 induces protective immune response to Neospora caninum in cattle. Vaccine, 31(35), 35283535 .

O'Connell, E., Wilkins, M. F., \& Te Punga, W. A. (1988). Toxoplasmosis in sheep II. The ability of a live vaccine to prevent lamb losses after an intravenous challenge with Toxoplasma gondii. New Zealand Veterinary Journal, 36(1), 1-4.
OIE (2014). World Organization for Animal Health Terrestrial Manual. Bovine Babesiosis. Chapter 2.4.2;2014.http://www.oie.int/fileadmin/Home/eng/H ealth_standards/tahm/2.04.02_BOVINE_BABESIOSI S. pdf.

Olson, M. E., Hannigan, C. J., Gaviller, P. F., \& Fulton, L. A. (2001). The use of a Giardia vaccine as an immunotherapeutic agent in dogs. The Canadian veterinary journal, 42(11), 865-868.

Özkoc, U., \& Pipano, E. (1981). Trials with cell culture vaccine against theileriosis in Turkey. In Advances in the Control of Theileriosis (pp. 256-258). Springer, Dordrecht.

Patel, E. H., Lubembe, D. M., Gachanja, J., Mwaura, S., Spooner, P., \& Toye, P. (2011). Molecular characterization of live Theileria parva sporozoite vaccine stabilates reveals extensive genotypic diversity. Veterinary Parasitology, 179(1-3), 62-68.

Radley, D. E., Brown, C. G. D., Cunningham, M. P., Kimber, C. D., Musisi, F. L., Payne, R. C., \& Young, A. S. (1975). East Coast fever: 3. Chemoprophylactic immunization of cattle using oxytetracycline and a combination of theilerial strains. Veterinary Parasitology, 1(1), 51-60.

Reichel, M. P., Moore, D. P., Hemphill, A., OrtegaMora, L. M., Dubey, J. P., \& Ellis, J. T. (2015). A live vaccine against Neospora caninum abortions in cattle. Vaccine. 33(11), 1299-1301.

Romero, J. J., Perez, E., \& Frankena, K. (2004). Effect of a killed whole Neospora caninum tachyzoite vaccine on the crude abortion rate of Costa Rican dairy cows under field conditions. Veterinary parasitology, 123(34), 149-159.

Sathish, K., Sriraman, R., Subramanian, B. M., Rao, N. H., Balaji, K., Narasu, M. L., \& Srinivasan, V. A. (2011). Plant expressed EtMIC2 is an effective immunogen in conferring protection against chicken coccidiosis. Vaccine, 29(49), 9201-9208.

Schetters, T. (2005). Vaccination against canine babesiosis. TRENDS in Parasitology, 21(4), 179-184.

Sharman, P. A., Smith, N. C., Wallach, M. G., \& Katrib, M. (2010). Chasing the golden egg: vaccination against poultry coccidiosis. Parasite immunology, 32(8), 590-598.

Shirley, M. W., \& Bedrnik, P. (1997). Live attenuated vaccines against avian coccidiosis: success with precocious and egg-adapted lines of Eimeria. Parasitology Today, 13(12), 481-484.

Shirley, M. W., Smith, A. L., \& Tomley, F. M. (2005). The biology of avian Eimeria with an emphasis on their control by vaccination. Advances in parasitology, 60 , 285-330.

Singh, A. K., Verma, A. K., Tiwari, R., Karthik, K., Dhama, K., \& Singh, S. V. (2014). Trends and advances in vaccines against protozoan parasites of veterinary importance: A review. Journal of Biological Sciences, 14(2), 95.

Song, X., Ren, Z., Yan, R., Xu, L., \& Li, X. (2015). Induction of protective immunity against Eimeria tenella, Eimeria necatrix, Eimeria maxima and Eimeria acervulina infections using multivalent epitope DNA vaccines. Vaccine, 33(24), 2764-2770. 
Tanner, M., \& Evans, D. (1994). Vaccines or drugs: complementarity is crucial. Parasitology today (Personal ed.), 10(10), 406-407.

Upadhayay, U. P. P. D. D., Ewam, P. C. V. V., Ewam, U. P. C. V. V., \& Sansthan, G. A. (2012). Immunomodulatory and Therapeutic Potentials of Herbal, Traditional/Indigenous and Ethnoveterinary Medicines" Mahima,“Anu Rahal," Rajib Deb, "Shyma K. Latheef," Hari Abdul Samad. Pakistan Journal of Biological Sciences, 15(16), 754-774.

Verma, A. K., Amit, K., Anu, R., \& Vinod, K. (2012). Veterinarian for the sustainable development of the humanity. Asian Journal of Animal and Veterinary Advances, 7(5), 452-453.

Verma, R., \& Khanna, P. (2013). Development of Toxoplasma gondii vaccine: a global challenge. Human vaccines \& immunotherapeutics, 9(2), 291-293.

Vermeulen, A. N., Schaap, D. C., \& Schetters, T. P. (2001). Control of coccidiosis in chickens by vaccination. Veterinary Parasitology, 100(1-2), 13-20.

Wallach, M. (2002). The development of CoxAbic $\AA$ a novel vaccine against coccidiosis. World Poultry, 18(2), 4.

Wang, J. L., Li, T. T., Elsheikha, H. M., Chen, K., Cong, W., Yang, W. B., \& Zhu, X. Q. (2018). Live Attenuated Pru: $\Delta$ cdpk2 Strain of Toxoplasma gondii Protects Against Acute, Chronic, and Congenital Toxoplasmosis. The Journal of infectious diseases, 218(5), 768-777.

Wang, J. L., Zhang, N. Z., Li, T. T., He, J. J., Elsheikha, H. M., \& Zhu, X. Q. (2019). Advances in the development of anti-Toxoplasma gondii vaccines: challenges, opportunities, and perspectives. Trends in parasitology, 35(3), 239-253.

Weston, J. F., Heuer, C., \& Williamson, N. B. (2012). Efficacy of a Neospora caninum killed tachyzoite vaccine in preventing abortion and vertical transmission in dairy cattle. Preventive veterinary medicine, 103(2-3), 136-144.

Wieser, S. N., Schnittger, L., Florin-Christensen, M., Delbecq, S., \& Schetters, T. (2019). Vaccination against babesiosis using recombinant GPI-anchored proteins. International journal for parasitology, 49(2), 175-181.

Williams, D. J., Guy, C. S., Smith, R. F., Ellis, J., Björkman, C., Reichel, M. P., \& Trees, A. J. (2007). Immunization of cattle with live tachyzoites of Neospora caninum confers protection against fetal death. Infection and immunity, 75(3), 1343-1348.

Williams, R. B. (2002). Fifty years of anticoccidial vaccines for poultry (1952-2002). Avian diseases, 46(4), 775-802.

Williams, R. B., Johnson, J. D., \& Andrews, S. J. (2000). Anticoccidial vaccination of broiler chickens in various management programmes: relationship between oocyst accumulation in litter and the development of protective immunity. Veterinary Research Communications, 24(5), 309-325.

Xu, J., Zhang, Y., \& Tao, J. (2013). Efficacy of a DNA vaccine carrying Eimeria maxima Gam56 antigen gene against coccidiosis in chickens. The Korean journal of parasitology, 51(2), 147.
Xu, L., \& Li, X. (2011). Vaccination of chickens with DNA vaccine expressing Eimeria tenella MZ5-7 against coccidiosis. Veterinary Parasitology, 177(12), 6-12.

Yin, H., Luo, J., \& Lu, W. (2008). Control of tropical theileriosis with attenuated schizont vaccine in China. Vaccine, 26, G11-G13. 